\title{
Early limited nitrosamine exposures exacerbate high fat diet-mediated type 2 diabetes and neurodegeneration
}

\author{
Ming Tong ${ }^{3,5}$, Lisa Longato ${ }^{3,4}$, Suzanne M de la Monte $1,2,3,45^{*}$
}

\begin{abstract}
Background: Type 2 diabetes mellitus (T2DM) and several types of neurodegeneration, including Alzheimer's, are linked to insulin-resistance, and chronic high dietary fat intake causes T2DM with mild neurodegeneration. Intracerebral Streptozotocin, a nitrosamine-related compound, causes neurodegeneration, whereas peripheral treatment causes DM.

Hypothesis: Limited early exposures to nitrosamines that are widely present in the environment, enhance the deleterious effects of high fat intake in promoting T2DM and neurodegeneration.

Methods: Long Evans rat pups were treated with N-nitrosodiethylamine (NDEA) by i.p. injection, and upon weaning, they were fed with high fat (60\%; HFD) or low fat (5\%; LFD) chow for 8 weeks. Cerebella were harvested to assess gene expression, and insulin and insulin-like growth factor (IGF) deficiency and resistance in the context of neurodegeneration.

Results: HFD \pm NDEA caused T2DM, neurodegeneration with impairments in brain insulin, insulin receptor, IGF-2 receptor, or insulin receptor substrate gene expression, and reduced expression of tau and choline acetyltransferase (ChAT), which are regulated by insulin and IGF-1. In addition, increased levels of 4-hydroxynonenal and nitrotyrosine were measured in cerebella of HFD \pm NDEA treated rats, and overall, NDEA+HFD treatment reduced

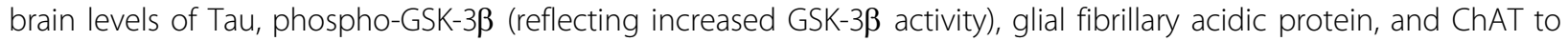
greater degrees than either treatment alone. Finally, pro-ceramide genes, examined because ceramides cause insulin resistance, oxidative stress, and neurodegeneration, were significantly up-regulated by HFD and/or NDEA exposure, but the highest levels were generally present in brains of HFD+NDEA treated rats.

Conclusions: Early limited exposure to nitrosamines exacerbates the adverse effects of later chronic high dietary fat intake in promoting T2DM and neurodegeneration. The mechanism involves increased generation of ceramides and probably other toxic lipids in brain.
\end{abstract}

\section{Background}

The prevalence rates of Alzheimer's Disease (AD), Parkinson's disease (PD), obesity, type 2 diabetes mellitus (T2DM), and metabolic syndrome have increased exponentially over the past several decades, and thus far show few hints of plateau [1-4]. The relatively short time interval flanking dramatic shifts in age-adjusted $\mathrm{AD}$ and PD mortality is consistent with exposure-related rather than genetic etiologies of these diseases. We have

\footnotetext{
* Correspondence: Suzanne_DeLaMonte_MD@Brown.edu

'Department of Pathology (Neuropathology), Rhode Island Hospital, 593 Eddy Street, Providence, RI 02903, USA
}

noted that the striking increases in AD and PD mortality rates followed sharply increased consumption of processed foods, use of preservatives, and demand for nitrogen-containing fertilizers [4]. A common theme resonating from these unnecessary lifestyle trends is that we have inadvertently increased our chronic exposures to nitrosamines $(\mathrm{R} 1 \mathrm{~N}(-\mathrm{R} 2)-\mathrm{N}=\mathrm{O})$ and related compounds.

Nitrosamines form by chemical reactions between nitrites and secondary amines or proteins. Nitrosamines exert their toxic and mutagenic effects by alkylating N-7 of guanine, leading to increased DNA damage [5] and 
generation of reactive oxygen species such as superoxide $\left(\mathrm{O}_{2}-\right)$ and hydrogen peroxide $\left(\mathrm{H}_{2} \mathrm{O}_{2}\right)$. Consequences include increased lipid peroxidation, protein adduct formation, and pro-inflammatory cytokine activation [6]. Of note is that these very same molecular and biochemical pathogenic cascades are activated in major human insulin-resistance diseases, including T2DM, non-alcoholic steatohepatitis (NASH), and AD [7-13]. The concept that chronic injury caused by exposure to alkylating agents could result in malignancy and/or tissue degeneration is not far-fetched given the facts that: 1) chronic exposures to tobacco nitrosamines cause both lung cancer and emphysema; and 2) treatment with streptozotocin (STZ), a nitrosamine-related compound, causes hepatocellular carcinoma, pancreatic carcinoma, malignant brain tumors, T2DM, AD-type neurodegeneration, and/or hepatic steatosis, depending on dose and route of administration [14-22]. Therefore, although research on nitrosamine-related compounds has been focused on their mutagenic properties, thorough characterization of their non-neoplastic and degenerative effects is clearly warranted. In this regard, guidance may be obtained from what is already known about STZ-induced diseases.

STZ, like other N-nitroso compounds, causes cellular injury and disease by functioning as: 1) an alkylating agent and potent mutagen [14]; 2) an inducer of DNA adducts leading to increased apoptosis [23]; 3) a mediator of unscheduled DNA synthesis, triggering cell death [14]; 4) an inducer of single-strand DNA breaks and stimulus for nitric oxide (NO) formation following breakdown of its nitrosamine group [16]; and 5) an enhancer of the xanthine oxidase system leading to increased production of superoxide anion, $\mathrm{H}_{2} \mathrm{O}_{2}$, and $\mathrm{OH}^{-}$radicals [24]. Ultimately, STZ-induced cellular injury, DNA damage, and oxidative stress cause mitochondrial dysfunction [16], ATP deficiency [25] and apoptosis. The structural similarities between STZ and nitrosamines, including N-nitrosodiethylamine (NDEA) and N-nitrosodimethylamine (NDMA) [26], together with experimental evidence that high doses of STZ cause cancer while lower doses cause diabetes or AD-type neurodegeneration with cognitive impairment $[15,16,22]$ led us to hypothesize that while high doses of environmental and consumed nitrosamines cause cancer, lower, submutagenic doses may promote insulin-resistance mediated degenerative diseases, including T2DM, AD, and possibly other neurological diseases.

Another key point is that obesity, T2DM, and cognitive impairment are likely inter-related, as suggested by the findings of: 1) increased risk for developing mild cognitive impairment (MCI), dementia, or AD in individuals with T2DM $[7,27]$ or obesity/dyslipidemic disorders [28]; 2) progressive brain insulin resistance and insulin deficiency in AD [29-32]; 3) cognitive impairment in experimental animal models of T2DM and/or obesity [33,34]; 4) AD-type neurodegeneration and cognitive impairment in experimentally induced brain insulin resistance and insulin deficiency [21,22,35-37]; 5) improved cognitive performance in experimental models of $\mathrm{AD}$ [19] and in human subjects with $\mathrm{AD}$ or MCI after treatment with insulin sensitizer agents or intranasal insulin [38-44]; and 6) similar molecular, biochemical, and mechanistic abnormalities in T2DM and AD [7-13]. On the other hand, recent studies showed that HFD feeding causes obesity, T2DM, and cognitive impairment, but is not sufficient to cause AD $[45,46]$. Therefore, it's likely that chronic HFD feeding which results in peripheral insulin resistance may provide a second-hit, and that combined with low-dose nitrosamine or other environmental exposures, it may increase the severity of neurodegeneration.

In the present study, we examined the hypothesis that chronic HFD feeding and limited exposure to sub-mutagenic doses of NDEA function additively to cause insulin resistance with T2DM and neurodegeneration. We focused our investigations on the cerebellum because, apart from subcortical neurodegenerative diseases such as multiple system atrophy (MSA) [47-51], progressive supranuclear palsy (PSP) [52], cerebellar ataxias $[48,53,54]$, PD $[52,55]$, and motor neuron disease (MND) [56], in which cognitive impairment has been linked to cerebellar degeneration, there is growing evidence that cerebellar degeneration is also a feature of AD [57-59], Lewy body dementia (LBD) $[60,61]$, and fronto-temporal dementia [62]. Although cerebellar degeneration in AD can be caused by superimposed PSP [63], MSA [64], or MND [65], it often occurs independently. Cerebellar degeneration in AD is manifested clinically by gait instability and increased falling [66], and structurally, by significant atrophy of the posterior cerebellar lobes, which correlates with cognitive impairment [67]. The major histopathological features of AD cerebellar atrophy include, reductions in Purkinje cell population, atrophy of the molecular and granule cell layers [68], increased amyloid deposition and gliosis in the cortex [69]; increased ubiquitin-immunoreactivity in senile plaques and degenerating neurites [70]; extensive abnormalities in dendritic spine density and synaptic structure in vestibulocerebellar, visual, and auditory pathways [71,72]; and degeneration of cerebellar white matter fibers with loss of climbing fibers and presynaptic varicosities [73]. In aggregate, synaptic pathology, rather than neurofibrillary tangles and plaques, represents the main correlate of cerebellar degeneration in AD.

In addition, cerebellar degeneration can be caused by systemic diseases such as diabetes mellitus [74], chronic 
alcoholism [75], or obesity with metabolic syndrome $[45,46]$. These systemic diseases share in common with primary central nervous system (CNS) degenerative diseases, impairments in cognition, and deficits in insulin and IGF signaling mechanisms, insulin/IGF responsive gene expression, and energy metabolism (glucose utilization) in the brain, including cerebellum [29,75-78]. Therefore, understanding the mechanisms by which lifestyle and environmental mediators promote neurodegeneration of the cerebellum has relevance to a broad spectrum of human CNS diseases.

\section{Methods}

\section{Materials}

Rabbit, mouse, or goat generated monoclonal or polyclonal antibodies to ubiquitin, tau, phospho-tau (AT8S199, S202, T205), glial fibrillary acidic protein (GFAP), 4-hydroxy-2-nonenal (HNE), choline acetyltransferase (ChAT), amyloid precursor protein amyloid- $\beta$ peptide $(\mathrm{A} \beta \mathrm{PP}-\mathrm{A} \beta), \beta$-actin, were purchased from Chemicon (Tecumsula, CA), CalBiochem (Carlsbad, CA), or Molecular Probes (Eugene, OR). All other polyclonal and monoclonal antibodies and immunodetection reagents were purchased from Abcam (Cambridge, MA), Vector Laboratories (Burlingame, CA), Upstate (Billerica, MA), Chemicon (Temecula, CA), or Molecular Probes (Eugene, OR). The insulin ultra-sensitive ELISA kit was obtained from ALPCO Diagnostics (Salem, NH). Histochoice fixative was purchased from Amresco, Inc (Solon, OH). Antibodies to tumor necrosis factor- $\alpha$ (TNF- $\alpha$ ) and interleukin-1 $\beta$ (IL-1 $\beta$ ) were purchased from Invitrogen (Carlsbad, CA). The Free Fatty Acid Assay kit was purchased from Roche Applied Science (Indianapolis, IN). Antibodies to GSK3 $\beta$, and phosphoGSK-3 $\beta$ (Ser9) were purchased from Cell Signaling (Danvers, MA). The OxyBlot assay for measuring protein carbonylation and the Milliplex-MAP Rat Adiponectin-Single Plex kit were purchased from Millipore Corp (Billerica, MA). The Amplex Red Cholesterol Assay Kit and Amplex UltraRed soluble fluorophore were purchased from Invitrogen (Carlsbad, CA). MaxiSorb 96-well plates used for ELISAs were from Nunc (Thermo Fisher Scientific; Rochester, NY). The MDA586 kit to measure malondialdehyde was purchased from Oxis International, Inc. (Foster City, CA). The anti-IL6 and Leptin ELISA kits were from Peprotech (Rocky Hill, NJ). The TopCount NXT and ATP Lite assay kit were from Perkin-Elmer (Waltham, MA). Superblock-TBS, horseradish peroxidase conjugated antibodies, and SuperSignal Enhanced Chemiluminescence Reagent were from Pierce Chemical Co (Rockford, IL). QIAzol Lysis Reagent for RNA extraction and QuantiTect SYBR Green PCR Mix were obtained from Qiagen, Inc (Valencia, CA). The AMV $1^{\text {st }}$ Strand cDNA
Synthesis kit was purchased from Roche Applied Science (Indianapolis, IN). The Serum Triglyceride Determination kit and synthetic oligonucleotides used in quantitative polymerase chain reaction (qPCR) assays were purchased from Sigma-Aldrich Co (St. Louis, MO). Fine chemicals were purchased from CalBiochem (Carlsbad, CA) or Sigma-Aldrich (St. Louis, MO).

\section{Experimental Model}

Postnatal day 3 (P3) Long Evans rat pups (mean body weight $10 \mathrm{~g}$ ) were given 3 alternate day intra-peritoneal (i.p.) injections of $20 \mu \mathrm{g}$ NDEA or vehicle. Upon weaning, male rats $(\mathrm{N}=8-10$ per group) were pair-fed for 8 weeks with high fat (HFD) or low fat (LFD) chow diets. The HFD supplied $60 \%$ of the $\mathrm{kcal}$ in fat $54 \%$ from lard, $6 \%$ from soybean oil), $20 \%$ in carbohydrates, and $20 \%$ in protein, whereas the LFD supplied $10 \%$ of the $\mathrm{kcal}$ in fat (4.4\% from lard, 5.6\% from soybean oil), 70\% in carbohydrates, and $20 \%$ in protein. Rats were weighed weekly, and food consumption was monitored daily. After an overnight fast (14 hours), rats were sacrificed by i.p. injection of pentobarbital $(120 \mathrm{mg} / \mathrm{kg})$. Blood and cerebella were harvested immediately. Blood or serum was used to measure glucose, insulin, cholesterol, triglycerides, and free fatty acid levels, as previously described $[45,46]$. Cerebella were harvested for histopathological, biochemical, and molecular studies. For histopathology, tissue samples were immersion fixed in Histochoice and embedded in paraffin. Histological sections (8- $\mu \mathrm{m}$ thick) were stained with Luxol Fast Blue, Hematoxylin, and Eosin (LHE) and examined under code. Adjacent sections were immunostained to detect glial fibrillary acidic protein (GFAP), ubiquitin, or 4-hydroxy-2-nonenal (HNE) as indices of neurodegeneration and oxidative stress as described elsewhere [79]. For molecular and biochemical assays, cerebella were snap-frozen in a dry ice-methanol bath and stored at $-80^{\circ} \mathrm{C}$. We studied cerebellar tissue because the cerebellum: 1 ) requires intact insulin/IGF signaling to maintain its structural and functional integrity $[80,81] ; 2)$ is severely damaged by i.c.-STZ mediated neurodegeneration [19,22]; 3) although relatively spared, it been shown to be a target of neurodegeneration in AD [57-59,82]; and 4) postmortem human studies demonstrated that AD cerebella exhibit insulin resistance [30]. Our experimental protocol was approved by the Institutional Animal Care and Use Committee at LifespanRhode Island Hospital, and conforms to the guidelines set by the National Institutes of Health.

\section{Quantitative Reverse Transcriptase Polymerase Chain Reaction (qRT-PCR) Assays of Gene Expression}

RNA was reverse transcribed using random oligodeoxynucleotide primers. The cDNAs of interest were amplified by PCR using gene specific primers (Table 1), and 
Table 1 Primer Pairs Used for Quantitative Reverse Transcriptase Polymerase Chain Reaction Assays

\begin{tabular}{|c|c|c|c|c|}
\hline Primer & Direction & Sequence $\left(5^{\prime} \rightarrow 3^{\prime}\right)$ & Position (mRNA) & Amplicon Size (bp) \\
\hline Insulin & For & TTC TAC ACA CCC AAG TCC CGT C & 145 & 135 \\
\hline Insulin & Rev & ATC CAC AAT GCC ACG CTT CTG C & 279 & \\
\hline Insulin Receptor & For & TGA CAA TGA GGA ATG TGG GGA C & 875 & 129 \\
\hline Insulin Receptor & Rev & GGG CAA ACT TTC TGA CAA TGA CTG & 1003 & \\
\hline$|G F-|$ & For & GAC CAA GGG GCT TTT ACT TCA AC & 65 & 127 \\
\hline$|G F-|$ & Rev & TाT GTA GGC TTC AGC GGA GCA C & 191 & \\
\hline IGF-I Receptor & For & GAA GTC TGC GGT GGT GAT AAA GG & 2138 & 113 \\
\hline IGF-| Receptor & Rev & TCT GGG CAC AAA GAT GGA GTT G & 2250 & \\
\hline$|G F-| \mid$ & For & CCA AGA AGA AAG GAA GGG GAC C & 763 & 95 \\
\hline |GF-|| & Rev & GGC GGC TAT TGT TGT TCA CAG C & 857 & \\
\hline |GF-I| Receptor & For & TTG CTA TTG ACC TTA GTC CCT TGG & 1066 & 91 \\
\hline |GF-|| Receptor & Rev & AGA GTG AGA CCT TTG TGT CCC CAC & 1156 & \\
\hline IRS-1 & For & GAT ACC GAT GGC TTC TCA GAC G & 604 & 134 \\
\hline IRS-1 & Rev & TCG TTC TCA TAA TAC TCC AGG CG & 737 & \\
\hline IRS-2 & For & CAA CAT TGA CTT TGG TGA AGG GG & 255 & 109 \\
\hline IRS-2 & Rev & TGA AGC AGG ACT ACT GGC TGA GAG & 263 & \\
\hline IRS-4 & For & ACC TGA AGA TAA GGG GTC GTC TGC & 2409 & 132 \\
\hline IRS-4 & Rev & TGT GTG GGG TIT AGT GGT CTG G & 2540 & \\
\hline ChAT & For & TCA CAG ATG CGT TTC ACA ACT ACC & 478 & 106 \\
\hline ChAT & Rev & TGG GAC ACA ACA GCA ACC TTG & 583 & \\
\hline AChE & For & TTC TCC CAC ACC TGT CCT CAT C & 420 & 123 \\
\hline AChE & Rev & TTC ATA GAT ACC AAC ACG GTT CCC & 542 & \\
\hline APP & For & GCA GAA TGG AAA ATG GGA GTC AG & 278 & 199 \\
\hline APP & Rev & AAT CAC GAT GTG GGT GTG CGT C & 476 & \\
\hline Tau & For & CGC CAG GAG TाT GAC ACA ATG & 244 & 65 \\
\hline Tau & Rev & CCT TCT TGG TCT TGG AGC ATA GTG & 308 & \\
\hline SPTLC-1 & For & CTAACCTTGGGCAAATCGAA & 2581 & 96 \\
\hline SPTLC-1 & Rev & TGAGCAGGGAGAAGGGACTA & 2676 & \\
\hline SPTLC-2 & For & GGA CAG TGT GTG GCC TाT CT & 1823 & 50 \\
\hline SPTLC-2 & Rev & TCA CTG AAG TGT GGC TCC TG & 1872 & \\
\hline CERS-1 & For & TGC GTG AAC TGG AAG ACT TG & 947 & 98 \\
\hline CERS-1 & Rev & CTT CAC CAG GCC ATT CCT TA & 1044 & \\
\hline CERS-2 & For & CTC TGC TTC TCC TGG TIT GC & 698 & 82 \\
\hline CERS-2 & Rev & CCA GCA GGT AGT CGG AAG AG & 779 & \\
\hline CERS-4 & For & CGA GGC AGT TTC TGA AGG TC & 1240 & 72 \\
\hline CERS-4 & Rev & CCA TTG GTA ATG GCT GCT CT & 1311 & \\
\hline CERS-5 & For & GAC AGT CCC ATC CTC TGC AT & 1254 & 92 \\
\hline CERS-5 & Rev & GAG GTT GTT CGT GTG TGT GG & 1345 & \\
\hline UGCG & For & GAT GCT TGC TGT TCA CTC CA & 2682 & 67 \\
\hline UGCG & Rev & GCT GAG ATG GAA GCC ATA GG & 2748 & \\
\hline SMPD-1 & For & CAG TTC TIT GGC CAC ACT CA & 1443 & 65 \\
\hline SMPD-1 & Rev & CGG CTC AGA GTT TCC TCA TC & 1507 & \\
\hline SMPD-3 & For & TCT GCT GCC AAT GTT GTC TC & 2704 & 98 \\
\hline SMPD-3 & Rev & CCG AGC AAG GAG TCT AGG TG & 2801 & \\
\hline
\end{tabular}

*Abbreviations: IGF = insulin-like growth factor; IRS = insulin receptor substrate; ChAT = choline acetyltransferase; AChE = acetylcholinesterase; APP = amyloid precursor protein; SPTLC = serine palmitoyltransferase; CERS = ceramide synthase; UGCG = UDP-glucose ceramide glucosyltransferae; SMPD = sphingomyelin phosphodiesterase; $\mathrm{bp}=$ base pair. 
the products were detected with the Mastercycler ep realplex instrument and software (Eppendorf AG, Hamburg, Germany) [45,83]. Relative mRNA abundance was calculated from the ratios of specific mRNA to $18 \mathrm{~S}$ measured in the same samples, and those data were used for inter-group statistical comparisons. Control studies included analysis of: 1) template-free reactions; 2) RNA that had not been reverse transcribed; 3) RNA samples pre-treated with DNAse I; 4) samples treated with RNAse A prior to the reverse transcriptase reaction; and 5) genomic DNA. All assays were performed in triplicate.

\section{Enzyme-Linked Immunosorbant Assay (ELISA)}

Tissue homogenates were prepared in radioimmunoprecipitation assay buffer containing protease and phosphatase inhibitors, as previously described [46]. Direct ELISAs were performed in 96-well Maxisorb plates [79]. In brief, proteins $(40 \mathrm{ng} / 100 \mu \mathrm{l})$ adsorbed to well bottoms by over night incubation at $4^{\circ} \mathrm{C}$, were blocked for 3 hours with 3\% BSA in Tris buffered saline (TBS), then incubated with primary antibody $(0.1-1.0 \mu \mathrm{g} / \mathrm{ml})$ for 1 hour at room temperature. Immunoreactivity was detected with horseradish peroxidase (HRP)-conjugated secondary antibody (1:10000) and Amplex Red soluble fluorophore [79]. Amplex Red fluorescence was measured (Ex 579/Em 595) in a SpectraMax M5 microplate reader (Molecular Devices Corp., Sunnyvale, CA). Negative control reactions included substitutions with nonrelevant primary or secondary antibodies, and omission of primary or secondary antibody. Immunoreactivities were normalized to protein content as determined with the NanoOrange Protein Quantification assay.

\section{Statistical Analysis}

Data depicted in the graphs and tables represent the means \pm S.E.M.'s for each group, with 8-10 samples included per group. Inter-group comparisons were made using one-way ANOVA and Bonferroni's multiple comparisons test for significance. Statistical analyses were performed using the GraphPad Prism 5 software (GraphPad Software, Inc., San Diego, CA). Software generated significant $\mathrm{P}$-values are shown in the graphs or included in the tables.

\section{Results}

\section{Effects of NDEA and HFD on Serum Biomarkers of T2DM}

\section{(Table 2)}

Mean body weights were higher in HFD fed relative to LFD fed rats. Mean fasting blood glucose and serum insulin concentrations were significantly lower in the LFD+VEH treated control group compared with all other groups. The mean levels of both serum glucose and insulin were next higher in the LFD+NDEA group, followed by the HFD group. The HFD+NDEA treated rats had the highest mean serum glucose and insulin levels. Correspondingly, serum leptin levels were significantly elevated in the HFD+VEH and HFD+NDEA treated relative to both LFD+VEH and LFD+NDEA groups. Serum adiponectin was lowest in the HFD+VEH group, and the difference relative to the HFD+NDEA treated group was statistically significant. Sera from rats in the HFD+VEH and HFD+NDEA treated groups had significantly lower mean triglyceride, free fatty acids, and cholesterol levels compared with LFD+VEH and LFD + NDEA treated groups. In addition, the serum free fatty acid level was significantly lower in the LFD+NDEA compared with LFD+VEH treated rats, whereas the triglyceride and cholesterol levels were similar in the two groups. Therefore, hyperglycemia, hyper-insulinemia, and hyper-leptinemia were features of chronic HFD feeding, and worsened by prior exposure to NDEA. In addition, early NDEA exposure alone was sufficient to cause mild but significant peripheral insulin resistance manifested by hyperglycemia and hyper-insulinemia in adults. In contrast, neither the NDEA exposure nor the chronic HFD feeding caused hyper-lapidarian, indicating that seemingly favorable serum lipid profiles can exist in

Table 2 High Fat Diet Feeding and NDEA Treatment Cause Type 2 Diabetes Mellitus

\begin{tabular}{|c|c|c|c|c|c|c|}
\hline Assay & LFD+VEH & LFD+NDEA & HFD+VEH & HFD+NDEA & F-Ratio & P-Value \\
\hline Body Wt (g) & $265.100 \pm 14.050$ & $266.600 \pm 19.970$ & $315.300 \pm 5.794$ & $308.400 \pm 15.110$ & 3.42 & 0.04 \\
\hline Glucose (mg/dL) & $111.5 \pm 1.66$ & $128.8^{*} \pm 4.31$ & $137.6^{* * *} \pm 2.39$ & $150.8^{* * *} \xi \pm 4.69$ & 18.2 & $<0.0001$ \\
\hline Insulin (ng/ml) & $0.0611 \pm 0.017$ & $0.163^{*} \pm 0.038$ & $0.324^{* *} \pm 0.074$ & $0.581^{* * *} \xi \pm 0.060$ & 22.69 & $<0.0001$ \\
\hline Leptin & $4.649 \pm 0.789$ & $4.775 \pm 0.386$ & $11.49^{* * *} \xi \pm 0.678$ & $15.73^{* * *} \xi \pm 1.473$ & 37.22 & $<0.0001$ \\
\hline Adiponectin & $20864 \pm 1454$ & $25195 \pm 3019$ & $16819 \xi \pm 1254$ & $26635 \pm 1962$ & 3.36 & 0.048 \\
\hline Triglyceride (mg/ml) & $0.399 \pm 0.028$ & $0.424 \pm 0.005$ & $0.173^{* * *} \xi \pm 0.011$ & $0.231^{* * *} \xi \pm 0.032$ & 38.2 & $<0.0001$ \\
\hline Free Fatty Acids (mM/mg prot) & $0.150 \pm 0.003$ & $0.114^{*} \pm 0.018$ & $0.081^{* * *} \xi \pm 0.002$ & $0.063^{* * *} \xi \pm 0.010$ & 21.9 & $<0.0001$ \\
\hline Cholesterol (mg/ml) & $0.943 \pm 0.024$ & $0.986 \pm 0.112$ & $0.552^{* * *} \xi \pm 0.051$ & $0.748^{* * *} \xi \pm 0.093$ & 6.53 & 0.004 \\
\hline
\end{tabular}

Serum samples obtained at sacrifice and after an over-night fast were studied. Inter-group comparisons were made using ANOVA with Bonferroni's Multiple Comparison Tests. For all measurements, $\mathrm{df}=3 / 36$. Asterisks reflect significant differences relative to the LFD+ Vehicle-treated $(V E H)$ control group $(* P<0.05 ; * * P$ $<0.01 ;{ }^{* * *} \mathrm{P}<0.001$ relative to LFD+VEH). $\xi$ = significant differences as follows: Glucose: $\mathrm{P}<0.05$ vs LFD+NDEA; Insulin: $\mathrm{P}<0.001$ vs LFD+NDEA; Adiponectin: $\mathrm{P}<$ 0.05 vs HFD+NDEA; Triglyceride: $\mathrm{P}<0.001$ vs LFD+NDEA; FFA: $\mathrm{P}<0.001$ vs LFD+NDEA; Cholesterol: $\mathrm{P}<0.001$ vs LFD+NDEA. 
the context of peripheral insulin resistance or T2DM. Similar results have been reported previously, in which the investigators generated models with much higher doses of NDEA [84]. One potential explanation for this paradox is that homeostatic mechanisms may have shifted toward increased storage of lipids/triglycerides in adipose tissue, skeletal muscle, and perhaps liver. Further studies will probe this hypothesis.

\section{Neuropathology of NDEA Exposure (Fig 1)}

The LFD-fed, vehicle-treated control rats had cerebella with complex foliation, tri-laminar cortical architecture with richly populated granule and Purkinje cell layers, and uniform white matter cores (Fig. 1-A1). HFD feeding alone produced subtle changes characterized by focal loss of Purkinje neurons (Fig. 1-A3). NDEA exposure, with or without chronic HFD feeding, resulted in loss of Purkinje cells (Figs. 1-A2, 1-A4) and variable thinning of the granule cell layer. Immunohistochemical staining demonstrated similar levels and distributions of GFAP immunoreactivity in cells distributed in the granule layer of control (Fig 1-B1) and HFD-fed (Fig 1-B3) rats, but reduced labeling in the NDEA-treated group (Fig 1-B2), and increased GFAP immunoreactivity in the NDEA+HFD treated group (Fig 1-B4). Control and NDEA-treated rats had similarly very low levels of HNE
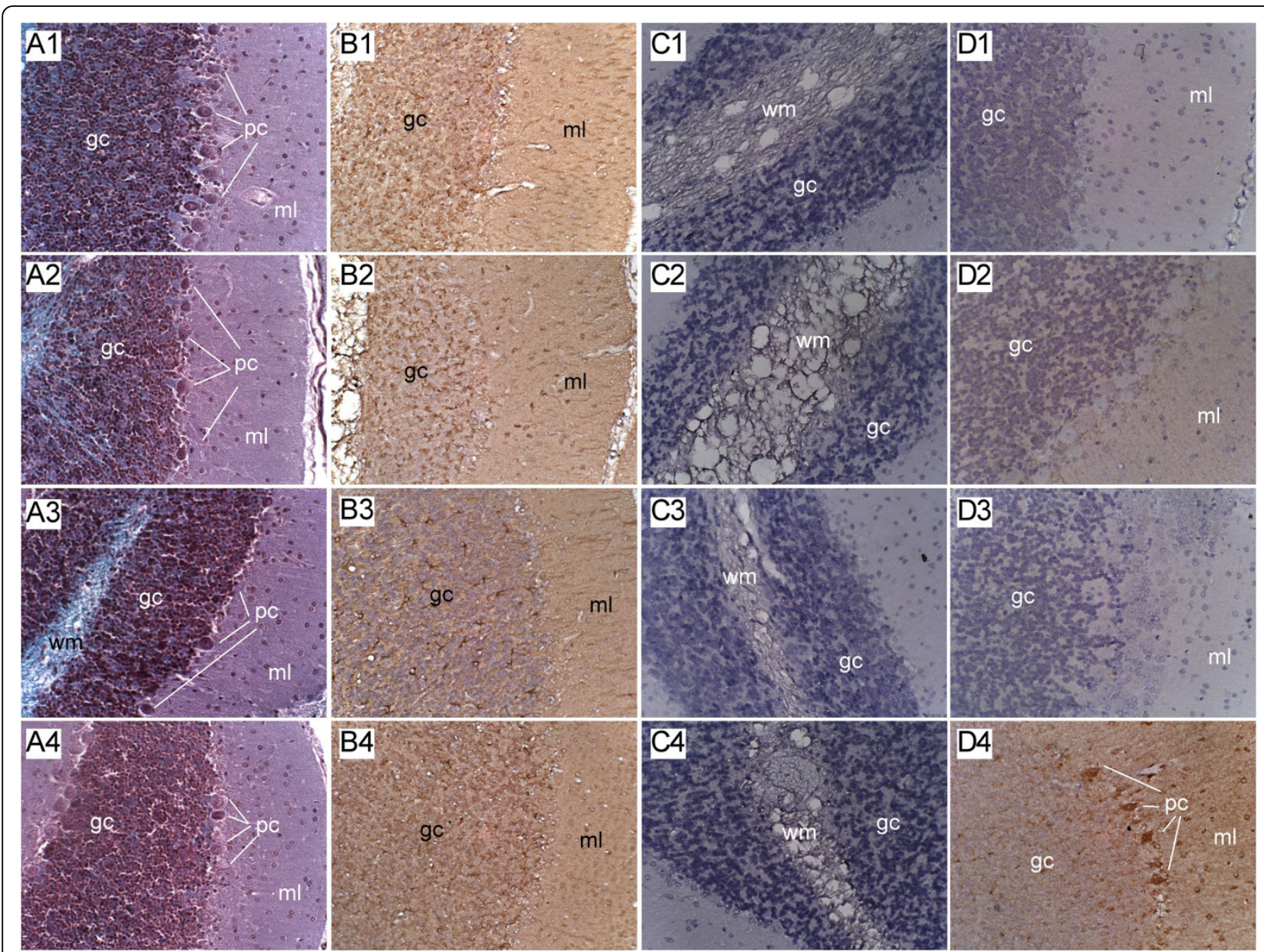

Figure 1 Cerebellar Degeneration in NDEA, HFD-Fed and NDEA+HFD Treated Rats. Long Evans rats were treated with 3 i.p. injections of vehicle or NDEA ( $N=12$ /group) on alternate days beginning on P3. From P21 (weaning), rats were fed with high fat (60\% of calories) or low fat ( $5 \%$ of calories) diets for 8 weeks, after which they were sacrificed to harvest cerebella for histopathological and immunohistochemical staining studies. Cerebella were preserved in Histofix and paraffin-embedded sections (8 microns) were stained with (A1-A4) Luxol fast blue, H\&E. Adjacent sections were immunostained to detect (B1-B4) GFAP, (C1-C4) HNE, or (D1-D4) ubiquitin. Representative photomicrographs of cerebellar cortex from (A1-D1) LFD+vehicle treated controls, (A2-D2) LFD+NDEA treated, (A3-D3) HFD+vehicle treated, and (A4-D4) HFD+NDEA treated rats are shown. Immunohistochemical staining was performed using the ABC method, and revealed with DAB (brown precipitate)-see Experimental Procedures. Sections were lightly counterstained with Hematoxylin (blue) to help reveal the tissue architecture. Cerebellar layers: $\mathrm{ml}=\mathrm{molecular}$ layer; $\mathrm{pc}=$ Purkinje cell layer; $\mathrm{gc}=$ granule cell layer; $w \mathrm{~m}=$ white matter. Note focal $\mathrm{pc}$ loss in A2, and large zones of pc loss in A3 and A4. (Original Magnifications $=400 x$ ). 
immunoreactivity in white matter (Figs. 1-C1, 1-C2), whereas rats fed with HFDs, with or without NDEA exposure, had increased HNE immunoreactivity in white matter cores (Figs. 1-C3, 1-C4). In addition, the white matter was more vacuolated, suggestive of increased myelin degeneration, in these two groups. Ubiquitin immunoreactivity was virtually undetectable in control and NDEA-exposed cerebella (Figs. 1-D1, 1-D2), but slightly increased in the Purkinje and granule cell layers of HFD-fed cerebella (Fig. 1-D3). Rats exposed to NDEA, and also chronically fed with the HFD, had prominently increased ubiquitin immunoreactivity in Purkinje cells, and diffusely increased labeling of fine cell process in the granule and molecular layers of the cerebellar cortex (Fig. 1-D4). The increased ubiquitin and HNE immunoreactivities in both cortex and white matter suggest that oxidative injury associated with NDEA + HFD feeding occurred in neuronal and glial cell populations.

\section{NDEA-Treatment Plus Chronic HFD Feeding Causes Sustained Abnormalities in Gene Expression Including Impairments in Insulin/IGF Signaling Mechanisms in the Brain}

We used qRT-PCR analysis to quantify long-term effects of NDEA \pm HFD exposure on amyloid precursor protein $(\mathrm{A} \beta \mathrm{PP}), \mathrm{Tau}$, choline acetyltransferase (ChAT), and acetylcholinesterase (AChE), i.e. molecular indices of neurodegeneration and cholinergic homeostasis. In addition, we measured gene expression corresponding to insulin and IGF polypeptides and receptors, and insulin receptor substrates (IRSs) that transmit signals required for growth, survival, energy metabolism, and neuronal plasticity downstream of the insulin and IGF receptors (Table 3). Early NDEA exposure alone was sufficient to significantly reduce the mean mRNA levels of $A \beta P P$ $(\mathrm{P}<0.05)$, Tau $(\mathrm{P}<0.01)$, insulin receptor $(\mathrm{P}<0.001)$, IGF-2 receptor $(\mathrm{P}<0.01)$, and IRS-2 $(\mathrm{P}<0.05)$ relative to control (LFD+VEH). Chronic HFD feeding significantly reduced ChAT $(\mathrm{P}<0.05)$ and IRS-1 $(\mathrm{P}<0.01)$ expression. HFD+NDEA reduced Tau $(\mathrm{P}<0.01)$, ChAT $(\mathrm{P}<0.05)$, and insulin $(\mathrm{P}<0.05)$, but had no significant effect on the mean mRNA levels of AChE, IGF-1, IGF2 , IGF-1 receptor, or IRS-4. Therefore, it appears that the inhibitory effects of NDEA on insulin receptor, IGF2 receptor, and IRS- 2 were muted by the chronic HFD feeding. Moreover, the main effect of NDEA, irrespective of HFD feeding, was to reduce tau gene expression, whereas chronic HFD feeding, irrespective of NDEA treatment, significantly inhibited ChAT. The only unique effect of HFD+NDEA treatment was to reduce insulin gene expression in the brain.

\section{Effects of NDEA and Chronic HFD Feeding on Protein Biomarkers of Neurodegeneration (Fig 2)}

ELISAs were used to measure sustained effects of NDEA treatment and/or chronic HFD feeding on Tau, phospho-Tau, A $\beta$ PP, A $\beta P P-A \beta, C h A T$, and AChE levels in brain tissue. Early limited exposure to NDEA significantly reduced the mean levels of pTau $(\mathrm{P}<0.001)$, A $\beta P P(P<0.01)$, ChAT $(\mathrm{P}<0.05)$, and AChE $(\mathrm{P}<0.01)$ relative to the levels measured in $\mathrm{LFD}+\mathrm{VEH}$ treated controls. In addition, in the LFD $\mathrm{VEH}$ group, the mean levels of pTau $(\mathrm{P}<0.001), \mathrm{A} \beta \mathrm{PP}(\mathrm{P}<0001)$, and AChE $(\mathrm{P}<0.05)$ were significantly lower than in the chronic HFD-fed group. Chronic HFD feeding alone

Table 3 Effects of High Fat Diet and NDEA Exposure on Biomarkers of Insulin and IGF Resistance in the Cerebellum

\begin{tabular}{|c|c|c|c|c|c|c|}
\hline mRNA & LFD+VEH & LFD+NDEA & HFD+VEH & HFD+NDEA & F-Ratio & P-Value \\
\hline$A \beta P P$ & $7.007 \pm 0.828$ & $3.129^{*} \xi \pm 0.309$ & $8.960 \pm 1.542$ & $6.796 \pm 1.287$ & 4.918 & 0.006 \\
\hline Tau & $12.230 \pm 1.098$ & $6.586^{* *} \xi \pm 1.329$ & $11.230 \pm 1.248$ & $7.284^{* *} \xi \pm 0.500$ & 6.612 & 0.001 \\
\hline AChE & $2.829 \pm 0.178$ & $4.171 \pm 0.698$ & $3.719 \pm 0.618$ & $3.562 \pm 0.412$ & & \\
\hline ChAT & $0.701 \pm 0.045$ & $0.780 \pm 0.122$ & $0.519^{*} \pm 0.039$ & $0.485^{*} \pm 0.037$ & 3.524 & 0.020 \\
\hline Insulin & $0.754 \pm 0.048$ & $0.617 \pm 0.047$ & $0.691 \pm 0.040$ & $0.584^{*} \pm 0.038$ & 3.065 & 0.040 \\
\hline IGF-1 & $0.957 \pm 0.119$ & $0.717 \pm 0.179$ & $0.558 \pm 0.063$ & $0.630 \pm 0.060$ & & \\
\hline IGF-2 & $12.000 \pm 1.800$ & $15.460 \pm 4.684$ & $17.930 \pm 6.163$ & $11.140 \pm 2.453$ & & \\
\hline Insulin R & $17.090 \pm 1.547$ & $7.59^{* * *} \xi \pm 0.808$ & $16.590 \pm 1.572$ & $16.170 \pm 1.685$ & 9.824 & $<0.001$ \\
\hline IGF-1R & $5.031 \pm 0.525$ & $4.331 \pm 0.982$ & $3.052 \pm 0.297$ & $4.511 \pm 0.392$ & & \\
\hline IGF-2R & $5.677 \pm 0.548$ & $2.641^{* *} \xi \pm 0.432$ & $5.289 \pm 0.693$ & $4.797 \pm 0.466$ & 6.201 & 0.002 \\
\hline IRS-1 & $5.559 \pm 0.411$ & $4.167 \pm 0.725$ & $3.254^{* *} \pm 0.207$ & $5.276 \pm 0.505$ & 4.532 & 0.009 \\
\hline IRS-2 & $7.701 \pm 0.509$ & $4.834^{*} \pm 0.934$ & $5.278 \pm 0.286$ & $7.571 \pm 1.198$ & 3.403 & 0.028 \\
\hline IRS-4 & $0.135 \pm 0.022$ & $0.104 \pm 0.024$ & $0.119 \pm 0.019$ & $0.091 \pm 0.017$ & & \\
\hline
\end{tabular}

Gene expression was measured by qRT-PCR with results normalized to $18 \mathrm{~S}$ rRNA (see Methods). Values correspond to mRNA/18S $\times 10^{-6}$. Inter-group comparisons were made using ANOVA and the post-hoc Bonferroni multiple comparison test. For all measurements, df $=3 / 36$. Asterisks ( ${ }^{*} \mathrm{P}<0.05 ;{ }^{*} \mathrm{P}<0.01 ;{ }^{* * *} \mathrm{P}<0.001$ ) reflect significant differences relative to LFD controls. $\xi=$ significant differences as follows: $A \beta P P$ : $P<0.05$ vs HFD+VEH and HFD+NDEA; Tau: $P<0.01$ vs HFD+VEH; ChAT: $\mathrm{P}<0.05$ vs LFD+NDEA; Insulin R: $\mathrm{P}<0.001$ vs HFD+VEH and HFD+NDEA; IGF-2R: $\mathrm{P}<0.001$ vs HFD+VEH and HFD vs NDEA; IRS-1: $\mathrm{P}<0.01$ vs $\mathrm{HFD}+\mathrm{NDEA}$ and $\mathrm{P}<0.05$ vs LFD+NDEA. 

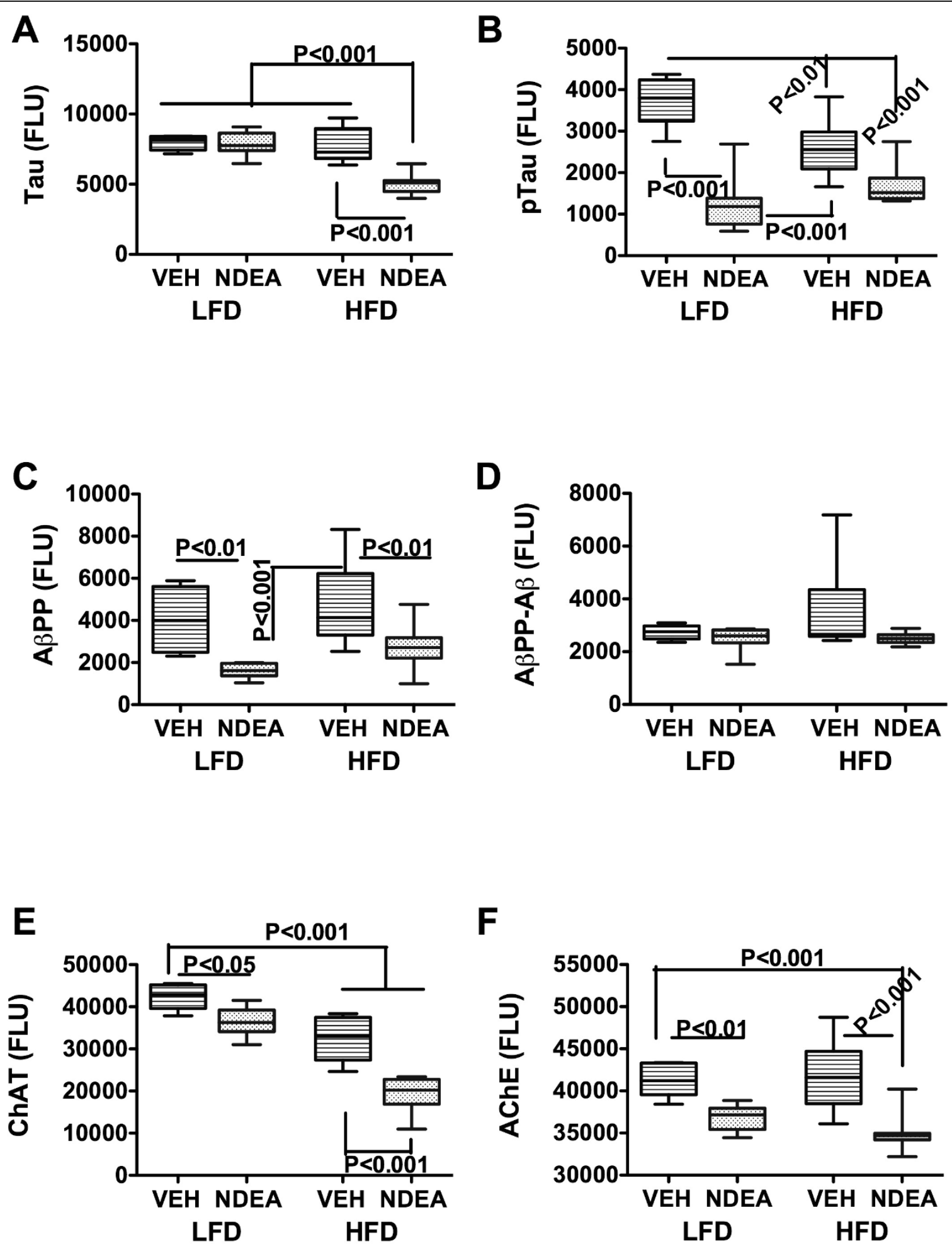

Figure 2 Effect of HFD feeding on molecular indices of AD-type neurodegeneration. Cerebellar protein homogenates were used to measure (A) Tau; (B) phospho (p)-Tau; (C) ABPP, (D) A BPP-AB, (E) choline acetyltransferase (ChAT); or (F) acetylcholinesterase (AChE) by direct binding ELISA. Immunoreactivity was detected with HRP-conjugated secondary antibody and Amplex Red soluble fluorophor. Fluorescence light units (FLU) were measured (Ex $579 \mathrm{~nm} / \mathrm{Em} 595 \mathrm{~nm}$ ) in a Spectromax M5, and results were normalized to sample protein content in the wells. Box plots depict mean, range \pm S.D. of results ( $N=8$-10/group). Inter-group comparisons were made using ANOVA with the post-hoc Bonferroni multiple comparisons test of significance. Significant P-values are indicated within the panels. 
$(\mathrm{HFD}+\mathrm{VEH})$ significantly reduced pTau $(\mathrm{P}<0.01)$ and ChAT $(\mathrm{P}<0.001)$ relative to control, whereas early NDEA exposure plus later chronic HFD feeding significantly reduced Tau $(\mathrm{P}<0.001)$, pTau $(\mathrm{P}<0.001)$, ChAT $(\mathrm{P}<0.001)$, and $\mathrm{AChE}(\mathrm{P}<0.001)$ relative to control and chronic HFD fed rats. In addition, the mean levels of Tau $(\mathrm{P}<0.001)$ and ChAT $(\mathrm{P}<0.001)$ were significantly lower in the HFD+NDEA compared with the LFD+NDEA treated group. Therefore, the major adverse effects of chronic HFD feeding were to significantly reduce $\mathrm{pTau}$ and ChAT immunoreactivities relative to control, while early limited exposure to NDEA significantly reduced pTau, A PPP, ChAT, and AChE. Combined exposure to HFD and NDEA produced similar effects as NDEA-treatment alone with regard to the reductions in $\mathrm{pTau}, \mathrm{A} \beta \mathrm{PP}$, and $\mathrm{AChE}$, but had additive or synergistic effects with regard to reductions in Tau and ChAT immunoreactivity.

\section{Effects of NDEA and Chronic HFD Feeding on Protein Biomarkers of Oxidative Injury and Inflammation (Fig 3)}

ELISAs were used to measure sustained effects of early limited NDEA treatment and/or chronic HFD feeding on

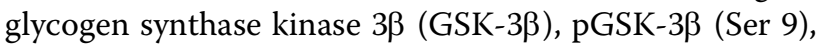
GFAP, glyceraldehydes-3-phosphate dehydrogenase (GAPDH), HNE, Nytrotyrosine, (N-Tyr), $\beta$-Actin, IL-1 $\beta$, TNF- $\alpha$, and IL- 6 immunoreactivities. In addition, we measured MDA and protein carbonylation levels in brain. The objective was to assess oxidative stress and biomarkers of injury. Early limited exposure to NDEA had no significant effect on any of the indices measured relative to control. Chronic HFD feeding significantly increased the mean levels of pGSK-3 $\beta$, GFAP, and N-Tyr relative to all other groups $(\mathrm{P}<0.05$ or better). Combined early limited NDEA exposure plus later chronic HFD feeding significantly reduced the mean levels of GSK-3 $\beta$ and GFAP relative to all other groups $(\mathrm{P}<0.01$ or better $)$, and $\mathrm{pGSK}-3 \beta$ and $\beta$ Actin relative to the LFD+VEH control (both $\mathrm{P}<0.05$ ) and HFD+VEH (both $\mathrm{P}<0.001$ ) treated groups. The finding of proportionally greater reductions in pGSK- $3 \beta$ relative to total GSK-3 $\beta$ in the HFD+NDEA group indicates that the combined treatments caused a net increase in activated GSK-3 $\beta$. The mean levels of HNE were similar in the HFD+VEH and HFD+NDEA groups, and both were significantly higher than in the LFD+VEH and LFD + NDEA groups $(\mathrm{P}<0.01)$. We did not detect significant inter-group differences with respect to MDA (Fig 3), protein carbonylation, or IL- $1 \beta$, TNF- $\alpha$, and IL-6 immunoreactivities (data not shown).

\section{NDEA-Mediated Increases in Pro-Ceramide Gene Expression}

We investigated the potential role of pro-ceramide genes as mediators of NDEA \pm HFD associated neurodegeneration because ceramides: 1) can be generated in brain [85-88]; 2) cause cytotoxicity and insulin resistance [83,88]; and 3) are increased in brains with neurodegeneration [85,89-91]. We measured mRNA levels of ceramide synthases (CER), UDP glucose ceramide glycosyltransferase (UGCG), serine palmitoyltransferase (SPTLC), and sphingomyelin phosphodiesterases (SMPD), due to their demonstrated relevance to neurodegeneration $[45,83]$. HFD feeding alone increased the mean levels of UGCG $(\mathrm{P}<0.01)$ and SPTLC2 $(\mathrm{P}<0.01)$, whereas NDEA treatment significantly reduced CER2 $(\mathrm{P}<0005)$, CER5 $(\mathrm{P}<0.001)$, and SPTLC1 $(\mathrm{P}<0.01)$, but increased UGCG $(\mathrm{P}<0.05)$ mRNA levels (Fig 4). HFD+NDEA feeding significantly increased CER2 $(\mathrm{P}<0.005)$, UGCG $(\mathrm{P}<0.001)$, SMPD1 $(\mathrm{P}<0.05)$, SMPD3 $(\mathrm{P}<0.001)$, and SPTLC2 $(\mathrm{P}<0.05)$, but decreased CER5 $(\mathrm{P}<0.001)$ relative to control. The unique effects of HFD+NDEA feeding compared with either treatment alone were to significantly increase CER2, SMPD1 and SMPD3 gene expression (Fig 4). NDEA and/or chronic HFD feeding did not significantly alter CER1 or CER4 gene expression.

\section{Discussion}

Our studies examined the degree to which limited early life NDEA exposure exacerbates the effects of chronic HFD feeding on the development of T2DM and neurodegeneration. The importance of this work is that morbidity and mortality rates from T2DM and neurodegeneration have soared over the past several decades, suggesting that exposures rather than genetics dictate their etiologies. Our over-arching hypothesis is that shifts in lifestyles and economics have led us to chronically consume excess fat, and get exposed to agents that cause insulin resistance. Consideration given to potential pathogenic agents was focused by the experimental evidence showing that STZ, a nitrosamine-related chemical, is mutagenic in high doses [14], but causes insulin-resistance diseases at lower levels or more limited durations of exposure, including early in life [15-22,92]. While STZ is generally not available to consumers, nitrosamines and related compounds are widely present in our environment and contaminate food sources. Therefore, we entertained the hypothesis that either limited or chronic low-level exposures to nitrosamines account for the observed shifts in morbidity and mortality from insulin resistance diseases. Moreover, given the clear role of high dietary fat intake as a mediator of obesity, T2DM, or cognitive impairment, we proposed that the combined effects of HFD and NDEA exposure may act additively or synergistically to cause insulin resistance diseases, including T2DM and neurodegeneration.

We generated an in vivo model in which rat pups were treated with NDEA at doses that were 5- to 



Figure 3 Effect of HFD feeding on molecular indices of oxidative stress and neurodegeneration. Cerebellar protein homogenates were used to measure (A) GSK-33; (B) phospho (p)-GSK-3B; (C) GFAP; (D) GAPDH; (E) HNE; (F) malondialdehyde, MDA; (G) Nitrotyrosine, N-TYR; or (H) $\beta$-Actin; by direct binding ELISA. Immunoreactivity was detected with HRP-conjugated secondary antibody and Amplex Red soluble fluorophor. Fluorescence light units (FLU) were measured (Ex $579 \mathrm{~nm} / \mathrm{Em} 595 \mathrm{~nm}$ ) in a Spectromax M5, and results were normalized to sample protein content in the wells. Box plots depict mean, range \pm S.D. of results ( $N=8-10 / g r o u p)$. Inter-group comparisons were made using ANOVA with the post-hoc Bonferroni multiple comparisons test of significance. Significant P-values are indicated within the panels.

500 -fold lower than the cumulative doses needed to produce cancer in experimental animals [93-96], and beginning in early adolescence, we pair-fed the rats with either high $(60 \%)$ or low (5\%) fat containing diets. The NDEA doses were selected to be far below those needed for carcinogenesis and were based on empirical studies demonstrating absence of acute toxic effects in the rats.
Longer durations of NDEA exposure were not used in order to avoid the possibility that the cumulative doses would lead to malignant transformation. The use of young rats enabled us to compare results with previous observations in the STZ model [81]. Moreover, longitudinal studies of nuns revealed that neuro-cognitive deficits precede the onset of dementia by decades $[97,98]$, 


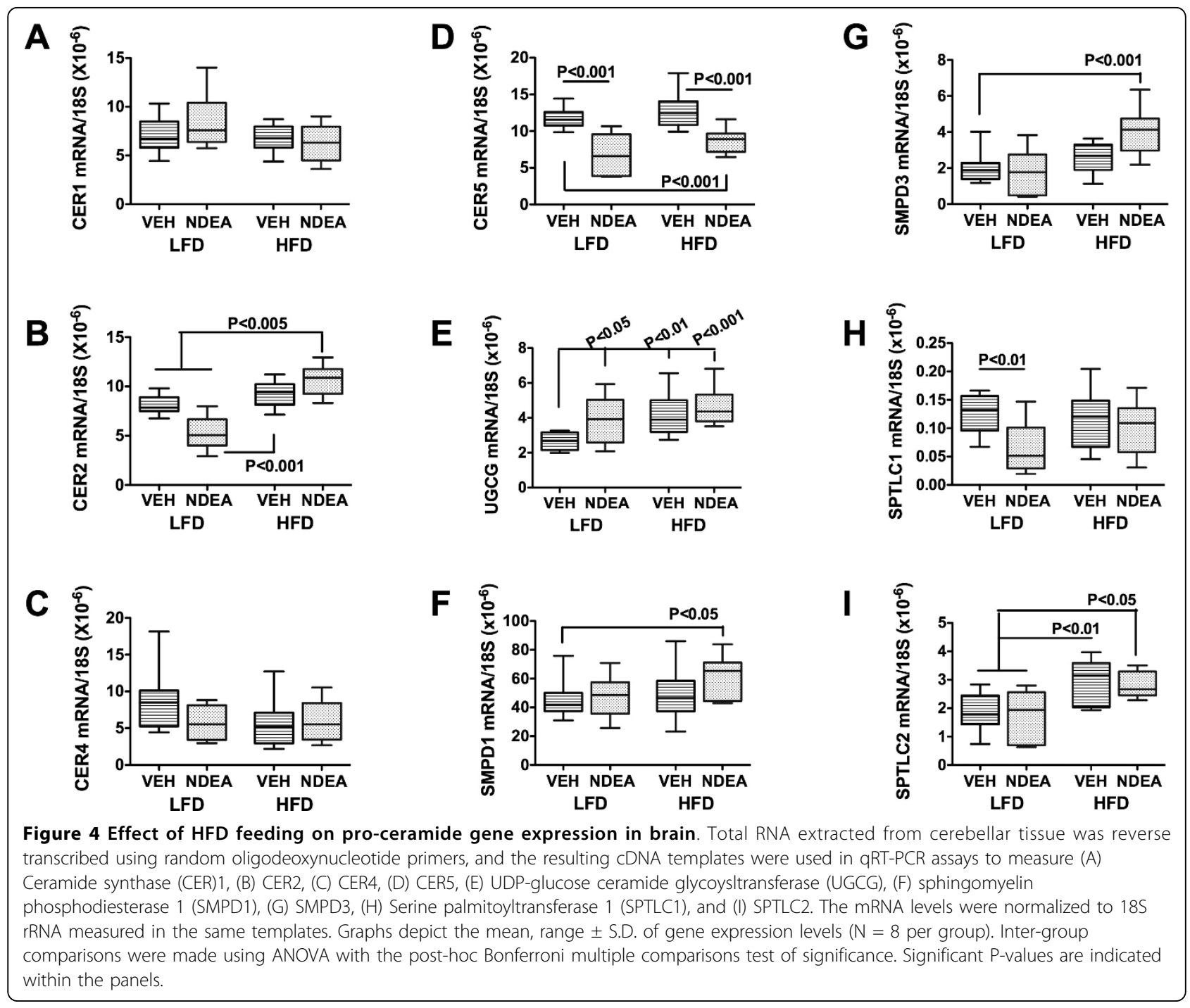

suggesting that early life exposures may contribute to the pathogenesis of $\mathrm{AD}$, perhaps through gene imprinting. Although chronic HFD feeding and limited NDEA exposure increased body weight and caused T2DM/peripheral insulin resistance with fasting hyperglycemia, hyper-insulinemia, and hyper-leptinemia [99,100], the rats were not obese and they did not have hyper-lipidemia. Instead, the serum lipid profile was favorable, consistent with a previous report of a related experimental model [84].

We focused our investigations on the cerebellum because the cerebellum can be adversely affected in AD, as well as other neurodegenerative diseases $[47,50$, $53,56,59,60,65,68,69,71]$, and cerebellar degeneration causes cognitive impairment $[49,57-59,62,63,66,67,72]$. Previous studies demonstrated significant structural, functional, and metabolic abnormalities in AD cerebella [57-59,82], including insulin and IGF resistance [30], similar to the findings in more traditional targets of $A D$, i.e. cortical and limbic structures. Finally, by focusing on one brain region, we were able to investigate a novel concept concerning potential additive or synergistic effects of double-hits, i.e. nitrosamine plus HFD exposures, on neurodegeneration in general.

Although both NDEA and HFD feeding caused structural injury and impaired gene expression in ways that could cause insulin/IGF resistance in the brain, their specific effects were not identical. The main effect of NDEA, with or without HFD feeding, was to reduce mRNA levels of insulin receptor, IGF-2 receptor, and IRS-2, which would have impaired signaling at the receptor level, and downstream through IRS-2, one of main docking proteins responsible for transmitting survival, growth, metabolism, and plasticity pathway signals $[80,81]$. Correspondingly, NDEA treatment inhibited tau and ChAT, which are regulated by insulin and IGF [81], 
and are reduced in brains with $\mathrm{AD}$ [81]. Reductions in tau, a major structural protein in CNS neurons, could result in cytoskeletal collapse and synaptic disconnection. Alternatively, the finding could reflect neuronal loss associated with neurodegeneration. The reduced levels of ChAT reflect deficits in acetylcholine homeostasis that contribute to cognitive impairment with neurodegeneration $[101,102]$. Correspondingly, in preliminary studies, we detected evidence of significant spatial learning and memory deficits in NDEA and NDEA+HFD treated rats by Morris Water Maze testing (Additional file 1, Table S1). The potential contribution of non-cerebral, specifically cerebellar degeneration to cognitive impairment was demonstrated in human subjects with $\mathrm{PD}$, whereby mild cognitive impairment was found to be associated with reduced nicotinic acetylcholine receptor binding in the cerebellum and brainstem [103].

In previous studies using a mouse model of dietinduced obesity $[45,46]$, we showed that chronic HFD feeding causes brain insulin resistance [46]. Similarly, herein we demonstrated that the HFD-fed rats had reduced levels of brain IRS-1 mRNA, which would have been sufficient to cause brain insulin resistance due to impaired transmission of insulin receptor activated signals; correspondingly, ChAT expression was reduced. In addition, HFD feeding increased GFAP, HNE, and NTyr immunoreactivities, consistent with findings in previous studies $[45,46]$, and providing further evidence that HFD feeding contributes to neurodegeneration by increasing gliosis/astrocyte activation and oxidative stress with lipid peroxidation, as occur in AD. The finding that chronic HFD feeding did not significantly alter tau or $A \beta P P$ expression also supports our previous conclusion that HFD feeding contributes to, but is not sufficient to cause AD-type neurodegeneration $[45,46]$.

The combined effect of early, limited NDEA exposure plus chronic HFD feeding significantly reduced insulin and ChAT mRNA levels, and ChAT, AChE, GSK-3 $\beta$, and pGSK- $3 \beta$ immunoreactivities. In addition, tau and ChAT expression levels were lowest in the HFD+NDEA group. Since tau and ChAT are regulated by insulin/IGF signaling [81], the impairment in insulin gene expression was likely pivotal in mediating these effects of HFD + NDEA exposure. In the HFD+NDEA group, both GSK-3 $\beta$ and pGSK- $3 \beta$ levels were reduced, but relative reductions were greater for pGSK-3 $\beta$ compared with total GSK-3 $\beta$, reflecting a net relative increased in GSK$3 \beta$ activity, similar to the findings in $A D$ and $P D$ in humans $[29,30,104]$. Therefore, HFD+NDEA treated rats exhibited persistent brain oxidative stress associated with increased levels of HNE (lipid peroxidation), NTyr, and GSK- $3 \beta$ activity. Although the NDEA exposure was delivered within a brief window during the human equivalent of childhood or early adolescence, its adverse effects on the brain were sustained into adulthood, similar to the findings with respect to the i.c.-STZ model $[19,22]$. Conceivably, such prolonged and possibly progressive deficits may occur because nitrosamines promote formation of DNA and protein adducts [105-107] that can serve as persistent sources of oxidative stress, and cause further DNA damage and protein dysfunction.

Recently, we demonstrated a role for ceramidemediated neurodegeneration in a model of diet-induced obesity with T2DM [45], and showed that in vitro ceramide exposure causes neurodegeneration with impairments in neuronal viability, energy metabolism and insulin/IGF signaling mechanisms [83], consistent with previous reports $[45,83,85,88-90,108-110]$. Moreover, other investigators have demonstrated significantly increased levels of ceramides and other sphingolipids in brains with neurodegeneration [76,90,110-114]. Therefore, we measured pro-ceramide mRNA levels to determine if the HFD or NDEA-associated neurodegeneration and insulin/IGF resistance were likely mediated by increased brain ceramide levels. Those studies demonstrated strikingly increased expression of several genes regulating ceramide production via both de novo biosynthesis or sphingomyelin degradation pathways in NDEA-treated rats, irrespective of chronic HFD feeding. Since NDEA is lipid soluble $[115,116]$ and can cross the blood-brain barrier [117], it is probable that the neurodegeneration with insulin/IGF resistance associated with limited NDEA exposure was mediated by direct and persistent neurotoxic effects of compound.

\section{Conclusions}

In conclusion, we have demonstrated that limited early exposure to sub-mutagenic doses of NDEA causes T2DM and neurodegeneration with impairments in insulin/IGF signaling mechanisms, and deficits in cholinergic and neuronal cytoskeletal gene and protein expression in brain, whereas chronic HFD feeding alone produces more restrictive deficits in insulin/IGF signaling mechanisms with reduced ChAT expression and increased oxidative stress. The combined exposures caused overlapping structural and molecular abnormalities that were additive with regard to the breadth of insulin/IGF signaling molecules that were impaired, and synergistic with respect to the degrees in which ChAT and tau expression were reduced and pro-ceramide genes increased. Since experimentally, exposure to neurotoxic ceramides produces similar effects, their increased levels in cerebrospinal fluid could serve as biomarkers of insulin-resistance mediated neurodegeneration. Finally, the findings suggest that our insulin resistance disease epidemics are linked to sub-mutagenic 
exposures to nitrosamines and related compounds, combined with chronic consumption of high fat content foods, indicating that these diseases are preventable.

Additional file 1: Effects of HFD and NDEA on Learning: Morris Water Maze Test. This supplementary table provides data showing adverse effects of NDEA exposure, chronic HFD feeding or both treatments on spatial learning and memory using the Morris Water Maze test.

\section{Abbreviations}

A $\beta$ PP: amyloid- $\beta$-precursor protein; A $\beta P P-A \beta$ : amyloid- $\beta$ peptide; AChE: acetylcholinesterase; AD: Alzheimer's disease; CER: Ceramide synthase; ChAT: choline acetyltransferase; ELISA: enzyme-linked immunosorbant assay; GFAP:

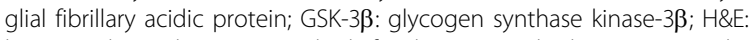
hematoxylin and eosin; HFD: high fat diet; HNE: 4-hydroxy-2-nonenal; HRP: horseradish peroxidase; i.p.: intraperitoneal; IGF: Insulin like growth factor; IRS: Insulin receptor substrate; LFD: low fat diet; LHE: Luxol fast blue hematoxylin and eosin; MCE: mild cognitive impairment; NASH: non-alcoholic steatohepatitis; NDEA: N-nitrosodiethylamine; NDMA: Nnitrosodimethylamine; P3: postnatal day 3; qRT-PCR: quantitative reverse transcriptase polymerase chain reaction; SMPD: sphingomyelin phosphodiesterase; SPTLC: Serine palmitoyltransferase; STZ: Streptozotocin; T2DM: Type 2 diabetes mellitus; TBS: Tris buffered saline; UGCG: UDP-glucose ceramide glycoysltransferase.

\section{Acknowledgements}

Supported by AA-11431, AA-12908, and K24-AA-16126 from the National Institutes of Health.

\section{Author details}

'Department of Pathology (Neuropathology), Rhode Island Hospital, 593 Eddy Street, Providence, RI 02903, USA. ²Department of Neurology, Rhode Island Hospital, 593 Eddy Street, Providence, RI 02903, USA. ${ }^{3}$ Liver Research Center, Rhode Island Hospital, 55 Claverick Street, Providence, RI 02903, USA. ${ }^{4}$ Pathobiology Program, Brown University, Box G, 222 Richmond Street, Providence, RI 02903, USA. ${ }^{5}$ Warren Alpert Medical School of Brown University, Box G, 97 Waterman Street, Providence, RI 02912, USA.

\section{Authors' contributions}

MT participated in the experimental design and the molecular and biochemical studies. LL contributed to the molecular and biochemical studies and participated in the data analysis. SMdIM conceived of the study, participated in the study design and coordination, performed statistical analysis, and drafted the manuscript. All authors read and approved the final manuscript.

\section{Competing interests}

The authors declare that they have no competing interests.

Received: 13 February 2009 Accepted: 19 March 2010 Published: 19 March 2010

\section{References}

1. Pradhan A: Obesity, metabolic syndrome, and type 2 diabetes: inflammatory basis of glucose metabolic disorders. Nutr Rev 2007, 65(12 Pt 2):S152-156.

2. Launer $\sqcup$ : Next steps in Alzheimer's disease research: interaction between epidemiology and basic science. Curr Alzheimer Res 2007, 4(2):141-143.

3. Wang XP, Ding HL: Alzheimer's disease: epidemiology, genetics, and beyond. Neurosci Bull 2008, 24(2):105-109.

4. de la Monte SM, Neusner A, Chu J, Lawton M: Epidemilogical Trends Strongly Suggest Exposures as Etiologic Agents in the Pathogenesis of Sporadic Alzheimer's Disease, Diabetes Mellitus, and Non-Alcoholic Steatohepatitis. J Alzheimers Dis 2009, 17(3):519-529.
5. Swann PF, Magee PN: Nitrosamine-induced carcinogenesis. The alklylation of nucleic acids of the rat by $\mathrm{N}$-methyl-N-nitrosourea, dimethylnitrosamine, dimethyl sulphate and methyl methanesulphonate. Biochem J 1968, 110(1):39-47.

6. Espey MG, Miranda KM, Thomas DD, Xavier S, Citrin D, Vitek MP, Wink DA: A chemical perspective on the interplay between NO, reactive oxygen species, and reactive nitrogen oxide species. Ann N Y Acad Sci 2002, 962:195-206

7. Pasquier F, Boulogne A, Leys D, Fontaine P: Diabetes mellitus and dementia. Diabetes Metab 2006, 32(5 Pt 1):403-414.

8. Nicolls MR: The clinical and biological relationship between Type II diabetes mellitus and Alzheimer's disease. Curr Alzheimer Res 2004 1(1):47-54.

9. Yeh MM, Brunt EM: Pathology of nonalcoholic fatty liver disease. Am J Clin Pathol 2007, 128(5):837-847.

10. Marchesini G, Marzocchi R: Metabolic syndrome and NASH. Clin Liver Dis 2007, 11(1):105-117, ix.

11. Papandreou D, Rousso I, Mavromichalis I: Update on non-alcoholic fatty liver disease in children. Clin Nutr 2007, 26(4):409-415.

12. Pessayre $D$ : Role of mitochondria in non-alcoholic fatty liver disease. J Gastroenterol Hepatol 2007, 22(Suppl 1):S20-27.

13. Wei Y, Rector RS, Thyfault JP, Ibdah JA: Nonalcoholic fatty liver disease and mitochondrial dysfunction. World I Gastroenterol 2008, 14(2):193-199.

14. Bolzan AD, Bianchi MS: Genotoxicity of streptozotocin. Mutat Res 2002, 512(2-3):121-134

15. Rossini AA, Like AA, Chick WL, Appel MC, Cahill GF Jr: Studies of streptozotocin-induced insulitis and diabetes. Proc Natl Acad Sci USA 1977, 74(6):2485-2489.

16. Szkudelski T: The mechanism of alloxan and streptozotocin action in B cells of the rat pancreas. Physiol Res 2001, 50(6):537-546.

17. Doi K: [Studies on the mechanism of the diabetogenic activity of streptozotocin and on the ability of compounds to block the diabetogenic activity of streptozotocin (author's transl)]. Nippon Naibunpi Gakkai Zasshi 1975, 51(3):129-147.

18. Iwai S, Murai T, Makino S, Min W, Morimura K, Mori S, Hagihara A, Seki S, Fukushima S: High sensitivity of fatty liver Shionogi (FLS) mice to diethylnitrosamine hepatocarcinogenesis: comparison to $\mathrm{C} 3 \mathrm{H}$ and $\mathrm{C} 57$ mice. Cancer Lett 2007, 246(1-2):115-121.

19. de la Monte SM, Tong M, Lester-Coll N, Plater M Jr, Wands JR: Therapeutic rescue of neurodegeneration in experimental type 3 diabetes: relevance to Alzheimer's disease. J Alzheimers Dis 2006, 10(1):89-109.

20. Hoyer S: Causes and consequences of disturbances of cerebral glucose metabolism in sporadic Alzheimer disease: therapeutic implications. Adv Exp Med Biol 2004, 541:135-152.

21. Hoyer S, Lannert H, Noldner M, Chatterjee SS: Damaged neuronal energy metabolism and behavior are improved by Ginkgo biloba extract (EGb 761). J Neural Transm 1999, 106(11-12):1171-1188.

22. Lester-Coll N, Rivera EJ, Soscia SJ, Doiron K, Wands JR, de la Monte SM: Intracerebral streptozotocin model of type 3 diabetes: relevance to sporadic Alzheimer's disease. J Alzheimers Dis 2006, 9(1):13-33.

23. Murata M, Takahashi A, Saito I, Kawanishi S: Site-specific DNA methylation and apoptosis: induction by diabetogenic streptozotocin. Biochem Pharmacol 1999, 57(8):881-887.

24. Nukatsuka M, Sakurai H, Yoshimura Y, Nishida M, Kawada J: Enhancement by streptozotocin of $\mathrm{O} 2$ - radical generation by the xanthine oxidase system of pancreatic beta-cells. FEBS Lett 1988, 239(2):295-298.

25. West IC: Radicals and oxidative stress in diabetes. Diabet Med 2000, 17(3):171-180

26. Robbiano L, Mereto E, Corbu C, Brambilla G: DNA damage induced by seven $\mathrm{N}$-nitroso compounds in primary cultures of human and rat kidney cells. Mutat Res 1996, 368(1):41-47.

27. Verdelho A, Madureira S, Ferro JM, Basile AM, Chabriat H, Erkinjuntti T, Fazekas F, Hennerici M, O'Brien J, Pantoni L, Salvadori E, Scheltens P, Visser MC, Wahlund LO, Waldemar G, Wallin A, Inzitari D: Differential impact of cerebral white matter changes, diabetes, hypertension and stroke on cognitive performance among non-disabled elderly. The LADIS study. J Neurol Neurosurg Psychiatry 2007, 78(12):1325-1330.

28. Martins IJ, Hone E, Foster JK, Sunram-Lea SI, Gnjec A, Fuller SJ, Nolan D, Gandy SE, Martins RN: Apolipoprotein E, cholesterol metabolism, diabetes, and the convergence of risk factors for Alzheimer's disease and cardiovascular disease. Mol Psychiatry 2006, 11(8):721-736. 
29. Rivera EJ, Goldin A, Fulmer N, Tavares R, Wands JR, de la Monte SM: Insulin and insulin-like growth factor expression and function deteriorate with progression of Alzheimer's disease: link to brain reductions in acetylcholine. J Alzheimers Dis 2005, 8(3):247-268.

30. Steen E, Terry BM, Rivera EJ, Cannon JL, Neely TR, Tavares R, Xu XJ, Wands JR, de la Monte SM: Impaired insulin and insulin-like growth factor expression and signaling mechanisms in Alzheimer's disease-is this type 3 diabetes? J Alzheimers Dis 2005, 7(1):63-80.

31. Craft S: Insulin resistance and Alzheimer's disease pathogenesis: potential mechanisms and implications for treatment. Curr Alzheimer Res 2007, 4(2):147-152.

32. Craft S: Insulin resistance syndrome and Alzheimer disease: pathophysiologic mechanisms and therapeutic implications. Alzheimer Dis Assoc Disord 2006, 20(4):298-301.

33. Winocur $G$, Greenwood CE: Studies of the effects of high fat diets on cognitive function in a rat model. Neurobiol Aging 2005, 26(Suppl 1):46-49.

34. Winocur G, Greenwood CE, Piroli GG, Grillo CA, Reznikov LR, Reagan LP, McEwen BS: Memory impairment in obese Zucker rats: an investigation of cognitive function in an animal model of insulin resistance and obesity. Behav Neurosci 2005, 119(5):1389-1395.

35. Weinstock M, Shoham S: Rat models of dementia based on reductions in regional glucose metabolism, cerebral blood flow and cytochrome oxidase activity. J Neural Transm 2004, 111(3):347-366.

36. Nitta A, Murai R, Suzuki N, Ito H, Nomoto H, Katoh G, Furukawa $Y$, Furukawa S: Diabetic neuropathies in brain are induced by deficiency of BDNF. Neurotoxicol Teratol 2002, 24(5):695-701.

37. Biju MP, Paulose CS: Brain glutamate dehydrogenase changes in streptozotocin diabetic rats as a function of age. Biochem Mol Biol Int 1998, 44(1):1-7.

38. Haan MN: Therapy Insight: type 2 diabetes mellitus and the risk of lateonset Alzheimer's disease. Nat Clin Pract Neurol 2006, 2(3):159-166.

39. Reger MA, Watson GS, Green PS, Wilkinson CW, Baker LD, Cholerton B, Fishel MA, Plymate SR, Breitner JC, Degroodt W, Mehta P, Craft S: Intranasal insulin improves cognition and modulates \{beta\}-amyloid in early AD. Neurology 2008, 70(6):440-448.

40. Landreth G: Therapeutic use of agonists of the nuclear receptor PPARgamma in Alzheimer's disease. Curr Alzheimer Res 2007, 4(2):159-164.

41. Watson GS, Bernhardt T, Reger MA, Cholerton BA, Baker LD, Peskind ER, Asthana S, Plymate SR, Frolich L, Craft S: Insulin effects on CSF norepinephrine and cognition in Alzheimer's disease. Neurobiol Aging 2006, 27(1):38-41.

42. Reger MA, Craft $\mathrm{S}$ : Intranasal insulin administration: a method for dissociating central and peripheral effects of insulin. Drugs Today (Barc) 2006, 42(11):729-739.

43. Reger MA, Watson GS, Frey WH, Baker LD, Cholerton B, Keeling ML, Belongia DA, Fishel MA, Plymate SR, Schellenberg GD, Cherrier MM, Craft S: Effects of intranasal insulin on cognition in memory-impaired older adults: modulation by APOE genotype. Neurobiol Aging 2006, 27(3):451-458.

44. Pedersen WA, McMillan PJ, Kulstad JJ, Leverenz JB, Craft S, Haynatzki GR: Rosiglitazone attenuates learning and memory deficits in Tg2576 Alzheimer mice. Exp Neurol 2006, 199(2):265-273.

45. Lyn-Cook LE Jr, Lawton $M$, Tong $M$, Silbermann E, Longato L, Jiao P, Mark $P$, Wands JR, Xu H, de la Monte SM: Hepatic Ceramide May Mediate Brain Insulin Resistance and Neurodegeneration in Type 2 Diabetes and Nonalcoholic Steatohepatitis. J Alzheimers Dis 2009, 16(4):715-729.

46. Moroz $\mathrm{N}$, Tong $\mathrm{M}$, Longato $\mathrm{L}, \mathrm{Xu} \mathrm{H}$, de la Monte SM: Limited Alzheimertype neurodegeneration in experimental obesity and type 2 diabetes mellitus. J Alzheimers Dis 2008, 15(1):29-44.

47. Gilman S, Quinn NP: The relationship of multiple system atrophy to sporadic olivopontocerebellar atrophy and other forms of idiopathic late-onset cerebellar atrophy. Neurology 1996, 46(5):1197-1199.

48. Gilman S, Sima AA, Junck L, Kluin KJ, Koeppe RA, Lohman ME, Little R: Spinocerebellar ataxia type 1 with multiple system degeneration and glial cytoplasmic inclusions. Ann Neurol 1996, 39(2):241-255.

49. Burk K, Globas C, Wahl T, Buhring U, Dietz K, Zuhlke C, Luft A, Schulz JB, Voigt K, Dichgans J: MRI-based volumetric differentiation of sporadic cerebellar ataxia. Brain 2004, 127(Pt 1):175-181.
50. Dickson DW, Lin W, Liu WK, Yen SH: Multiple system atrophy: a sporadic synucleinopathy. Brain Pathol 1999, 9(4):721-732.

51. Jellinger KA, Seppi K, Wenning GK: Grading of neuropathology in multiple system atrophy: proposal for a novel scale. Mov Disord 2005, 20(Suppl 12):S29-36.

52. Paviour DC, Price SL, Stevens JM, Lees AJ, Fox NC: Quantitative MRI measurement of superior cerebellar peduncle in progressive supranuclear palsy. Neurology 2005, 64(4):675-679.

53. Berciano J: Olivopontocerebellar atrophy. A review of 117 cases. J Neurol Sci 1982, 53(2):253-272.

54. Mizutani T: [Neuropathological background of spinocerebellar degeneration-with special reference to autonomic nervous system lesions in olivopontocerebellar atrophy, Shy-Drager syndrome and multiple system atrophy]. No To Shinkei 1985, 37(7):675-685.

55. Ibarretxe-Bilbao N, Ramirez-Ruiz B, Junque C, Marti MJ, Valldeoriola F, Bargallo N, Juanes S, Tolosa E: Differential progression of brain atrophy in Parkinson disease with and without visual hallucinations. J Neurol Neurosurg Psychiatry 2009.

56. Averback P, Crocker P: Regular involvement of Clarke's nucleus in sporadic amyotrophic lateral sclerosis. Arch Neurol 1982, 39(3):155-156.

57. Ishii K, Sasaki M, Kitagaki H, Yamaji S, Sakamoto S, Matsuda K, Mori E: Reduction of cerebellar glucose metabolism in advanced Alzheimer's disease. J Nucl Med 1997, 38(6):925-928.

58. Larner AJ: The cerebellum in Alzheimer's disease. Dement Geriatr Cogn Disord 1997, 8(4):203-209.

59. Wegiel J, Wisniewski HM, Dziewiatkowski J, Badmajew E, Tarnawski M, Reisberg B, Mlodzik B, De Leon MJ, Miller DC: Cerebellar atrophy in Alzheimer's disease-clinicopathological correlations. Brain Res 1999, 818(1):41-50.

60. Mori F, Piao YS, Hayashi S, Fujiwara H, Hasegawa M, Yoshimoto M, Iwatsubo T, Takahashi H, Wakabayashi K: Alpha-synuclein accumulates in Purkinje cells in Lewy body disease but not in multiple system atrophy. J Neuropathol Exp Neurol 2003, 62(8):812-819.

61. Tu PH, Robinson KA, de Snoo F, Eyer J, Peterson A, Lee VM, Trojanowski JQ: Selective degeneration fo Purkinje cells with Lewy body-like inclusions in aged NFHLACZ transgenic mice. J Neurosci 1997, 17(3):1064-1074.

62. Cairns NJ, Grossman M, Arnold SE, Burn DJ, Jaros E, Perry RH, Duyckaerts C, Stankoff B, Pillon B, Skullerud K, Cruz-Sanchez FF, Bigio EH, Mackenzie IR, Gearing M, Juncos JL, Glass JD, Yokoo H, Nakazato Y, Mosaheb S, Thorpe JR, Uryu K, Lee VM, Trojanowski JQ: Clinical and neuropathologic variation in neuronal intermediate filament inclusion disease. Neurology 2004, 63(8):1376-1384

63. Bigio $E H$, Vono $M B$, Satumtira S, Adamson J, Sontag E, Hynan $L S$, White $C L$, Baker M, Hutton M: Cortical synapse loss in progressive supranuclear palsy. J Neuropathol Exp Neurol 2001, 60(5):403-410.

64. Rusina R, Bourdain F, Matej R: [Multiple system atrophy and Alzheimer's disease: a case report of a rare association of two neuro-degenerative disorders]. Rev Neurol (Paris) 2007, 163(12):1239-1241.

65. Engel PA, Grunnet M: Atypical dementia and spastic paraplegia in a patient with primary lateral sclerosis and numerous necortical beta amyloid plaques: new disorder or Alzheimer's disease variant? I Geriatr Psychiatry Neurol 2000, 13(2):60-64.

66. Sheridan PL, Hausdorff JM: The role of higher-level cognitive function in gait: executive dysfunction contributes to fall risk in Alzheimer's disease. Dement Geriatr Cogn Disord 2007, 24(2):125-137.

67. Thomann PA, Schlafer C, Seidl U, Santos VD, Essig M, Schroder J: The cerebellum in mild cognitive impairment and Alzheimer's disease - a structural MRI study. J Psychiatr Res 2008, 42(14):1198-1202.

68. Bertoni-Freddari C, Fattoretti P, Casoli T, Caselli U, Meier-Ruge W: Deterioration threshold of synaptic morphology in aging and senile dementia of Alzheimer's type. Anal Quant Cytol Histol 1996, 18(3):209-213.

69. Fukutani Y, Cairns NJ, Rossor MN, Lantos PL: Cerebellar pathology in sporadic and familial Alzheimer's disease including APP 717 (Val->lle) mutation cases: a morphometric investigation. J Neurol Sci 1997, 149(2):177-184.

70. Dickson DW, Wertkin A, Mattiace LA, Fier E, Kress Y, Davies P, Yen SH: Ubiquitin immunoelectron microscopy of dystrophic neurites in cerebellar senile plaques of Alzheimer's disease. Acta Neuropathol 1990, 79(5):486-493. 
71. Baloyannis SJ: Dendritic pathology in Alzheimer's disease. J Neurol SCi 2009, 283(1-2):153-157.

72. Baloyannis SJ, Manolidis SL, Manolidis LS: Synaptic alterations in the vestibulocerebellar system in Alzheimer's disease-a Golgi and electron microscope study. Acta Otolaryngol 2000, 120(2):247-250.

73. Baloyannis SJ: Pathological alterations of the climbing fibres of the cerebellum in vascular dementia: a Golgi and electron microscope study. J Neurol Sci 2007, 257(1-2):56-61.

74. Carson MJ, Slager UT, Steinberg RM: Simultaneous occurrence of diabetes mellitus, diabetes insipidus, and optic atrophy in a brother and sister. Am J Dis Child 1977, 131(12):1382-1385.

75. de la Monte SM, Tong M, Cohen AC, Sheedy D, Harper C, Wands JR: Insulin and insulin-like growth factor resistance in alcoholic neurodegeneration. Alcohol Clin Exp Res 2008, 32(9):1630-1644.

76. de la Monte SM: Insulin resistance and Alzheimer's disease. BMB Rep 2009, 42(8):475-481.

77. Giovannone B, Tsiaras WG, de la Monte S, Klysik J, Lautier C, Karashchuk G, Goldwurm S, Smith RJ: GIGYF2 gene disruption in mice results in neurodegeneration and altered insulin-like growth factor signaling. Hum Mol Genet 2009, 18(23):4629-4639.

78. Busiguina S, Fernandez AM, Barrios V, Clark R, Tolbert DL, Berciano J, TorresAleman I: Neurodegeneration is associated to changes in serum insulinlike growth factors. Neurobiol Dis 2000, 7(6 Pt B):657-665.

79. Cohen AC, Tong M, Wands JR, de la Monte SM: Insulin and insulin-like growth factor resistance with neurodegeneration in an adult chronic ethanol exposure model. Alcohol Clin Exp Res 2007, 31(9):1558-1573.

80. de la Monte SM, Wands JR: Review of insulin and insulin-like growth factor expression, signaling, and malfunction in the central nervous system: relevance to Alzheimer's disease. J Alzheimers Dis 2005, 7(1):45-61.

81. de la Monte SM, Wands JR: Alzheimer's Disease is Type 3 Diabetes: Evidence Reviewed. J Diabetes Science Tech 2008, 2(6):1101-1113.

82. Cole G, Neal JW, Singhrao SK, Jasani B, Newman GR: The distribution of amyloid plaques in the cerebellum and brain stem in Down's syndrome and Alzheimer's disease: a light microscopical analysis. Acta Neuropathol 1993, 85(5):542-552.

83. Tong M, de la Monte SM: Mechanisms of ceramide-mediated neurodegeneration. J Alzheimers Dis 2009, 16(4):705-714.

84. Hietanen E, Bartsch H, Ahotupa M, Bereziat JC, Bussacchini-Griot V, Cabral JR, Camus AM, Laitinen M, Wild H: Mechanisms of fat-related modulation of N-nitrosodiethylamine-induced tumors in rats: organ distribution, blood lipids, enzymes and pro-oxidant state. Carcinogenesis 1991, 12(4):591-600.

85. Alessenko AV, Bugrova AE, Dudnik LB: Connection of lipid peroxide oxidation with the sphingomyelin pathway in the development of Alzheimer's disease. Biochem Soc Trans 2004, 32(Pt 1):144-146.

86. Laviad EL, Albee L, Pankova-Kholmyansky I, Epstein S, Park H, Merrill AH Jr, Futerman AH: Characterization of ceramide synthase 2: tissue distribution, substrate specificity, and inhibition by sphingosine 1phosphate. J Biol Chem 2008, 283(9):5677-5684.

87. Shah C, Yang G, Lee I, Bielawski J, Hannun YA, Samad F: Protection from high fat diet-induced increase in ceramide in mice lacking plasminogen activator inhibitor 1. J Biol Chem 2008, 283(20):13538-13548.

88. Summers SA: Ceramides in insulin resistance and lipotoxicity. Prog Lipid Res 2006, 45(1):42-72.

89. Adibhatla RM, Hatcher JF: Altered Lipid Metabolism in Brain Injury and Disorders. Subcell Biochem 2008, 48, nihpa41041.

90. Katsel P, Li C, Haroutunian V: Gene expression alterations in the sphingolipid metabolism pathways during progression of dementia and Alzheimer's disease: a shift toward ceramide accumulation at the earliest recognizable stages of Alzheimer's disease? Neurochem Res 2007, 32(4-5):845-856.

91. Nakane M, Kubota M, Nakagomi T, Tamura A, Hisaki H, Shimasaki H, Ueta N: Lethal forebrain ischemia stimulates sphingomyelin hydrolysis and ceramide generation in the gerbil hippocampus. Neurosci Lett 2000, 296(2-3):89-92.

92. Weiland D, Mondon CE, Reaven GM: Evidence for multiple causality in the development of diabetic hypertriglyceridaemia. Diabetologia 1980, 18(4):335-340.

93. Lijinsky W, Reuber MD, Riggs CW: Dose response studies of carcinogenesis in rats by nitrosodiethylamine. Cancer Res 1981, 41(12 Pt 1):4997-5003.
94. Lijinsky W, Saavedra JE, Reuber MD: Induction of carcinogenesis in Fischer rats by methylalkylnitrosamines. Cancer Res 1981, 41(4):1288-1292.

95. Bansal AK, Bansal M, Soni G, Bhatnagar D: Protective role of Vitamin E pretreatment on $\mathrm{N}$-nitrosodiethylamine induced oxidative stress in rat liver. Chem Biol Interact 2005, 156(2-3):101-111.

96. Clapp NK, Craig AW, Toya RE Sr: Diethylnitrosamine oncogenesis in RF mice as influenced by variations in cumulative dose. Int I Cancer 1970, 5(1):119-123.

97. Butler SM, Ashford JW, Snowdon DA: Age, education, and changes in the Mini-Mental State Exam scores of older women: findings from the Nun Study. J Am Geriatr Soc 1996, 44(6):675-681.

98. Snowdon DA, Kemper SJ, Mortimer JA, Greiner LH, Wekstein DR, Markesbery WR: Linguistic ability in early life and cognitive function and Alzheimer's disease in late life. Findings from the Nun Study. JAMA 1996, 275(7):528-532.

99. lizuka S, Suzuki W, Tabuchi M, Nagata M, Imamura S, Kobayashi Y, Kanitani M, Yanagisawa T, Kase Y, Takeda S, Aburada M, Takahashi KW: Diabetic complications in a new animal model (TSOD mouse) of spontaneous NIDDM with obesity. Exp Anim 2005, 54(1):71-83.

100. Figueroa CD, Taberner PV: Pancreatic islet hypertrophy in spontaneous maturity onset obese-diabetic CBA/Ca mice. Int J Biochem 1994, 26(1011):1299-1303.

101. Davis KL, Mohs RC, Marin D, Purohit DP, Perl DP, Lantz M, Austin G, Haroutunian V: Cholinergic markers in elderly patients with early signs of Alzheimer disease. JAMA 1999, 281(15):1401-1406,

102. Dunnett SB, Fibiger HC: Role of forebrain cholinergic systems in learning and memory: relevance to the cognitive deficits of aging and Alzheimer's dementia. Prog Brain Res 1993, 98:413-420.

103. Meyer PM, Strecker K, Kendziorra K, Becker G, Hesse S, Woelpl D, Hensel A, Patt M, Sorger D, Wegner F, Lobsien D, Barthel H, Brust P, Gertz HJ, Sabri O, Schwarz J: Reduced alpha4beta2*-nicotinic acetylcholine receptor binding and its relationship to mild cognitive and depressive symptoms in Parkinson disease. Arch Gen Psychiatry 2009, 66(8):866-877.

104. Tong M, Dong M, de la Monte SM: Brain insulin-like growth factor and neurotrophin resistance in Parkinson's disease and dementia with Lewy bodies: potential role of manganese neurotoxicity. J Alzheimers Dis 2009, 16(3):585-599.

105. Chhabra SK, Souliotis VL, Kyrtopoulos SA, Anderson LM: Nitrosamines, alcohol, and gastrointestinal tract cancer: recent epidemiology and experimentation. In Vivo 1996, 10(3):265-284.

106. Hashimoto K, Takasaki W, Sato I, Tsuda S: DNA damage measured by comet assay and 8-OH-dG formation related to blood chemical analyses in aged rats. J Toxicol Sci 2007, 32(3):249-259.

107. Myers SR, Ali MY: Haemoglobin adducts as biomarkers of exposure to tobacco-related nitrosamines. Biomarkers 2008, 13(2):145-159.

108. Holland WL, Knotts TA, Chavez JA, Wang LP, Hoehn KL, Summers SA: Lipid mediators of insulin resistance. Nutr Rev 2007, 65(6 Pt 2):S39-46.

109. Kraegen EW, Cooney GJ: Free fatty acids and skeletal muscle insulin resistance. Curr Opin Lipidol 2008, 19(3):235-241.

110. Wang G, Silva J, Dasgupta S, Bieberich E: Long-chain ceramide is elevated in presenilin 1 (PS1M146V) mouse brain and induces apoptosis in PS1 astrocytes. Glia 2008, 56(4):449-456.

111. Cutler RG, Kelly J, Storie K, Pedersen WA, Tammara A, Hatanpaa K, Troncoso JC, Mattson MP: Involvement of oxidative stress-induced abnormalities in ceramide and cholesterol metabolism in brain aging and Alzheimer's disease. Proc Natl Acad Sci USA 2004, 101(7):2070-2075.

112. Han X, D MH, McKeel DW Jr, Kelley J, Morris JC: Substantial sulfatide deficiency and ceramide elevation in very early Alzheimer's disease: potential role in disease pathogenesis. J Neurochem 2002, 82(4):809-818.

113. Mattson MP, Barger SW, Furukawa K, Bruce AJ, Wyss-Coray T, Mark RJ, Mucke L: Cellular signaling roles of TGF beta, TNF alpha and beta APP in brain injury responses and Alzheimer's disease. Brain Res Brain Res Rev 1997, 23(1-2):47-61.

114. Gottfries CG, Karlsson I, Svennerholm L: Membrane components separate early-onset Alzheimer's disease from senile dementia of the Alzheimer type. Int Psychogeriatr 1996, 8(3):365-372.

115. Pylypiw HM, Zubroff JR, Magee PN, Harrington GW: The metabolism of $\mathrm{N}$ nitrosomethylaniline. J Cancer Res Clin Oncol 1984, 108(1):66-70.

116. Singer GM, Taylor HW, Lijinsky W: Liposolubility as an aspect of nitrosamine carcinogenicity: quantitative correlations and qualitative observations. Chem Biol Interact 1977, 19(2):133-142. 
117. Hinuma K, Matsuda J, Tanida N, Hori S, Tamura K, Ohno T, Kano M,

Shimoyama T: $\mathrm{N}$-nitrosamines in the stomach with special reference to in vitro formation, and kinetics after intragastric or intravenous administration in rats. Gastroenterol Jpn 1990, 25(4):417-424.

\section{Pre-publication history}

The pre-publication history for this paper can be accessed here: [http://www.biomedcentral.com/1472-6823/10/4/prepub]

doi:10.1186/1472-6823-10-4

Cite this article as: Tong et al:: Early limited nitrosamine exposures exacerbate high fat diet-mediated type 2 diabetes and neurodegeneration. BMC Endocrine Disorders 2010 10:4.

Submit your next manuscript to BioMed Central and take full advantage of:

- Convenient online submission

- Thorough peer review

- No space constraints or color figure charges

- Immediate publication on acceptance

- Inclusion in PubMed, CAS, Scopus and Google Scholar

- Research which is freely available for redistribution

Submit your manuscript at www.biomedcentral.com/submit
C Biomed Central 